\title{
Quantitative genetics of growth and development in Populus. II. The partitioning of genotype $x$ environment interaction in stem growth
}

\author{
R. WU \& R. F. STETTLER* \\ College of Forest Resources, Box 352100, University of Washington, Seattle, WA 98195-2100, U.S.A.
}

\begin{abstract}
Two interspecific hybrid pedigrees of Populus trichocarpa and $P$. deltoides, each containing parental, $F_{1}$ and $F_{2}$ generations, and planted in two contrasting environments in northern Oregon, served to estimate the interactions of genotypes $\times$ environments for stem growth during the first two years of growth. All three generations showed greater mean growth in the warm, high-radiation, and well-watered regime of the interior (Boardman) than in the cooler coastal conditions of Clatskanie. In the two $F_{2}$ families, all stem traits displayed significant genotype $\times$ environment interactions which accounted for $\approx 10$ per cent of the total phenotypic variance. Genetic correlations across environments were larger for basal area and volume growth than for stem height and proportion. Genotype $\times$ environment interaction variance was further partitioned into two components attributable to the heterogeneity of genetic variance between environments and the lack of genetic correlation across environments. For radial and volume growth, a large amount of genotype $\times$ environment interaction was associated with the heterogeneity of genetic variance across environments. For stem height and proportion, lack of genetic correlation across environments explained more of the genotype $\times$ environment interaction. The Spearman rank correlations of phenotypic means between the two environments were moderately high but significantly less than unity in most cases. Much of the growth difference in the two $\mathrm{F}_{2}$ families had a significant genetic component, with broad-sense heritabilities at each location ranging from $0.70-0.90$. The implications for breeding and selection of superior poplars for these environments are discussed.
\end{abstract}

Keywords: broad-sense heritability, environmental sensitivity, genetic correlation, growth, Populus.

\section{Introduction}

The increasing interest in intensive poplar culture for fibre and energy (Ranney et al., 1987; Abelson, 1991) demands a better understanding of key determinants of productivity in Populus L. and the ways they can be manipulated genetically and culturally. A common way to approach this genetically is to cross parents that differ in various components of productivity and to study their segregating progeny in the $\mathrm{F}_{2}$ or $\mathrm{F}_{3}$ generations (e.g. Paterson et al., 1991; Stuber et al., 1992). Such studies have also been conducted with poplar, making use of two distinct species, $P$. deltoides from the eastern US, and

\footnotetext{
${ }^{*}$ Correspondence. E-mail: stettler@poplar1.cfr.washington.edu
}

Populus trichocarpa from the Pacific Coast (Wu \& Stettler, 1994; Bradshaw \& Stettler, 1995). Hybrids between the two are among the fastest-growing trees of the temperate zone (Ranney et al., 1987; Heilman $\&$ Stettler, 1990). They are interfertile and amenable to advanced-generation analysis. Studies of such an interspecific pedigree, both via quantitative-genetic and molecular means, have shown tree height and diameter growth to be: (i) under the control of few (3-5) quantitative trait loci (QTLs) with major effect; and (ii) closely associated with specific components of crown architecture, often mapping to the same chromosomal location (Wu \& Stettler, 1994; Bradshaw \& Stettler, 1995).

To date this information has been derived from a single pedigree, grown in a single plantation in the 
Puget Sound lowland of Washington, west of the Cascade Range. An effort was made therefore to broaden the genetic material and to challenge it with two distinct environments that might elicit differential phenotypic responses, or genotype $\times$ environment $(G \times E)$ interactions.

The genetic mechanisms underlying the interactions of genotypes and 'predictable' or 'unpredictable' environments (Allard \& Bradshaw, 1964) have been extensively studied in such agronomic crops as maize, wheat, tomato and rice (Paterson et al., 1991; Stuber et al., 1992; Cooper \& DeLacy, 1994). By contrast, forest trees are less well understood, partly because of their complexity, partly because of the heterogeneous environment they inhabit. Genetic variation in environmental sensitivity has been observed in trees at all hierarchical levels, from species (Bazzaz et al., 1990; Drew \& Chapman, 1992) to provenance (Namkoong \& Conkle, 1976) to family (Namkoong et al., 1992) and individual (Ledig, 1970). Poplars occupy a somewhat intermediate position between forest trees and agricultural crops; although still carrying the genetic legacy of a long-lived species adapted to the variable environment of a riparian habitat, they are commonly grown as clonally propagated woody crops on carefully prepared sites in uniform plantations.

In this paper we present data from two hybrid poplar pedigrees, grown in replicated plantations in two contrasting environments of northern Oregon, one maritime, the other continental. The following questions will be addressed. (i) How important is the component of variance attributable to $\mathrm{G} \times \mathrm{E}$ interaction in determining the total phenotypic variance for stem growth? (ii) How much of the genetic response to the two environments is shared, and does the $G \times E$ interaction affect the relative rankings of genotypes? (iii) What are broad-sense heritabilities for growth traits, and does the environment have a large impact on their values?

\section{Materials and methods}

\section{Plant pedigrees and experimental plantations}

In 1981, two $F_{1}$ hybrid families were generated from crosses between a female Populus trichocarpa parent (93-968), native to western Washington, and two different male $P$. deltoides parents. One male parent, ILL-129 from central Illinois, gave rise to Family 53, the other, ILL-005 from southern Illinois, to Family 50 (Fig. 1). In 1988, two clones of Family 53, 53-246 and 53-242, were crossed to produce $F_{2}$ family 331 .

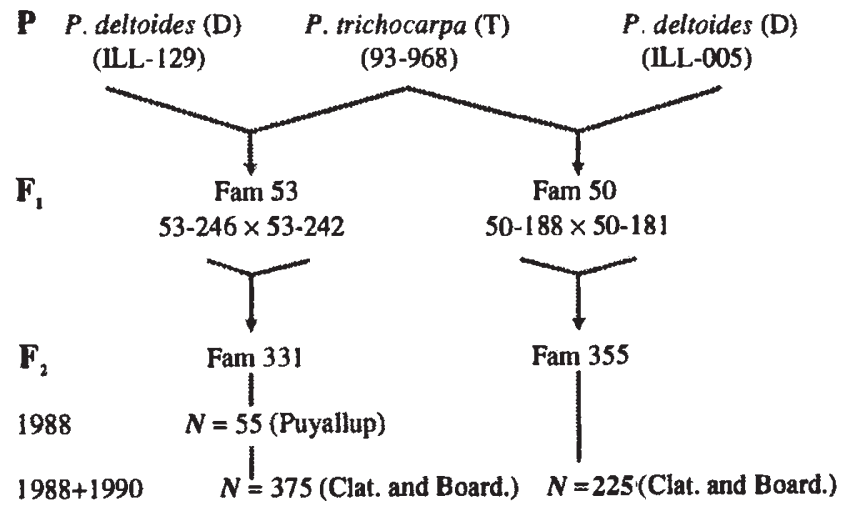

Fig. 1 The pedigrees of Populus used in the study. Clone 93-968, used as the common female parent for the two pedigrees, was native to western Washington. Male clones ILL-129 and ILL-005 were from central and southern Illinois, respectively.

In 1990, the same cross was repeated to augment this $\mathrm{F}_{2}$ family to $N=375$. At the same time, an additional $\mathrm{F}_{2}$ family (355) was generated from crossing two $F_{1}$ clones of Family 50, 50-181 and 50-188. Both inbred pedigrees were maintained in a nursery at Farm 5 of the Washington State University Research and Extension Centre in Puyallup, Washington.

In spring 1993, rooted cuttings of this material (including the 1988 subset of Family 331) were planted in two environments, one east of the Cascades in Boardman, Oregon, the other west of the Cascades in the lower Columbia River Valley near Clatskanie, Oregon. Both plantations contain 375 and 225 genotypes of Families 331 and 355, respectively, as well as their corresponding $F_{1}$ parents and grandparents, laid out in a randomized complete block design with two-tree plots at a spacing of $1.5 \times 3.0 \mathrm{~m}$ and surrounded by two border rows. Three replicates were used in the Clatskanie plantation, four at Boardman. To minimize competitive interactions among this highly varied material in the two plantations, each genotype was assigned to one of three size classes, based on its previous year's growth in the nursery. The three classes were laid out perpendicularly to the blocks in ascending and descending order. A triploid clone identified in Family 331 (Bradshaw \& Stettler, 1993) was excluded from all genetic analyses.

The two plantation environments differ markedly, Boardman $\left(117^{\circ} 6^{\prime} \mathrm{W}, 45^{\circ} 42^{\prime} \mathrm{N}\right)$ being in a continental climate, whereas Clatskanie $\left(123^{\circ} 40^{\prime} \mathrm{W}\right.$, $46^{\circ} 6^{\prime} \mathrm{N}$ ) is in the coastal zone with strong maritime influence. During the growing season (April- 
October) of 1994 , the average monthly temperature was $18.5^{\circ} \mathrm{C}$ at Boardman, $14.3^{\circ} \mathrm{C}$ at Clatskanie. The average solar irradiance in that year at Boardman was $430 \mathrm{~W} \mathrm{~m}^{-2} \mathrm{day}^{-1}$, compared to $280 \mathrm{~W} \mathrm{~m}^{-2}$ day $^{-1}$ at Clatskanie. The total annual precipitation for 1994 was $20.1 \mathrm{~cm}$ at Boardman, $135.1 \mathrm{~cm}$ at Clatskanie. At Clatskanie, the soil is an alluvial silt loam of the Columbia River Valley with a $\mathrm{pH}$ of $\approx 5.0$ near the surface, and an organic matter content of about 5 per cent in the top $20 \mathrm{~cm}$. Its general fertility is high, requiring no supplemental amendment. At Boardman, the soil is a sandy loam, with a $\mathrm{pH}$ of 7.0-7.5, an organic matter content of $\approx 1$ per cent near the surface and negligible in the subsoil, and low fertility. From April to October of 1993, trees in all four replicates at Boardman were uniformly irrigated weekly by means of a trickle irrigation system, with a total of $82.2 \mathrm{~cm}$. The same water amount was used for the first three replicates but reduced to $52.1 \mathrm{~cm}$ in replicate IV during 1994 . In each year, fertilizer was applied via irrigation water at the rate of $50-80 \mathrm{~kg} \mathrm{~N} / \mathrm{ha}, 20 \mathrm{~kg} \mathrm{P} / \mathrm{ha}$, and $5 \mathrm{~kg} \mathrm{~K} / \mathrm{ha}$.

\section{Trait measurements and analyses}

Stem height and diameter were measured at the end of the first and second year. In year 1, diameter was measured $3 \mathrm{~cm}$ above the ground, in year 2 at the mid-point of the first-year height increment. Stem cross-section area and volume index were estimated by $(\text { diameter })^{2} / 4 \pi$ and (height $) \times(\text { diameter })^{2}$, respectively.

Data analyses were based on two analysis of variance models. The first was used to test the effects of environment, genotype, replicate within environments, genotype $\times$ environment, and genotype $\times$ replicate within environment in each $F_{2}$ family. The variance components for these effects were calculated by equating the mean squares with the expected mean squares derived from Type III sums of squares, PROC GLM (sas Institute, 1988). In this study, the 'variance' accounted for by growth environments was also calculated, although the environments were considered a fixed effect as a result of their nonrandom sampling.

If $G \times E$ interactions were significant, the changes in genetic variance and heritability over environments were examined using a second model. The model detects the effects of genotype, replicate, and genotype $\times$ replicate interactions in each environment. Assuming that all these terms are random, the various components of variance were estimated by equating the mean squares to the corresponding expected values and solving the ensuing equations.
As derived from the principles of quantitative genetic analysis (Mather \& Jinks, 1982), the accuracy for estimating genetic variance based on a single $F_{2}$ family relies on whether all loci affecting a quantitative trait (QTLs) are fixed for alternative alleles in the two parents. When this condition is met, the estimated genetic variance is unbiased, that is, the variance explained by the genotype effects in the $F_{2}$ family can exactly represent the total genetic variance of the trait in a random mating population in Hardy-Weinberg equilibrium. However, any deviation from this condition would lead to an underestimate for the total genetic variance. Hence, estimation of genetic variance from the $F_{2}$ family can be extended to a general case only when this deviation is negligible.

The estimated genetic variance was used to calculate the genetic correlation between performance of a trait in two environments from Robertson's (1959) formula:

$r_{\mathrm{g}}=\frac{\sigma_{\mathrm{g}_{1}}}{\sigma_{\mathrm{g}_{2}}}+\frac{\sigma_{\mathrm{g}_{2}}}{\sigma_{\mathrm{g}_{1}}}-1-\frac{2 \sigma_{\mathrm{GE}}^{2}}{\sigma_{\mathrm{g}_{1}} \sigma_{\mathrm{g}_{2}}}$,

where $\sigma_{\mathrm{g}_{1}}$ and $\sigma_{\mathrm{g}_{2}}$ are the square roots of genetic variance in the two environments, respectively, and $\sigma_{\mathrm{GE}}^{2}$ is the interaction variance between genotypes and environments. The genetic correlation across environments can quantify the degree to which expression of a trait in one environment shares a heritable genetic basis with the expression of the same trait in a different environment (Via \& Lande, 1985; Falconer, 1989). The test for the genetic correlation is based on two sets of null hypotheses using likelihood ratio statistics. (i) The genetic correlation is zero. When this hypothesis is rejected, the performance expressed in each of the two environments has a shared genetic basis. If the genetic correlation is significantly less than 0 , then there is genotype $\times$ environment interaction in the form of genetically based trade-offs between performance in the two environments. (ii) The genetic correlation of performance in the two environments equals one. When this hypothesis is rejected, there exists $\mathrm{G} \times \mathrm{E}$ interaction such that genetic variation in the environmental response cannot be accounted for simply by differences in genetic variance between environments. The standard errors of genetic correlation were determined following Robertson (1959).

Based on $\sigma_{\mathrm{g}_{1}}, \sigma_{\mathrm{g}_{2}}$, and $r_{\mathrm{g}}$, the $\mathrm{G} \times \mathrm{E}$ interaction variance is further partitioned into two components attributable to heterogeneity of genetic variance $\left[V\left(\sigma_{\mathrm{g}}\right)\right]$ and the lack of genetic correlation between environments $\left[L\left(r_{\mathrm{g}}\right)\right]$, i.e. 
$\sigma_{\mathrm{GE}}^{2}=V\left(\sigma_{\mathrm{g}}\right)+L\left(r_{\mathrm{g}}\right)$,

$V\left(\sigma_{\mathrm{g}}\right)=\frac{1}{2}\left(\sigma_{\mathrm{g}_{1}}-\sigma_{\mathrm{g}_{2}}\right)^{2}$,

$L\left(r_{\mathrm{g}}\right)=\frac{1}{2} \sigma_{\mathrm{g}_{1}} \sigma_{\mathrm{g}_{2}}\left(1-r_{\mathrm{g}}\right)$,

where $V\left(\sigma_{\mathrm{g}}\right)$ can be expressed as the variance of the standard genetic deviation components between environments. When the genetic correlation between environments is one, $L\left(r_{g}\right)$ will equal zero and there will be no $G \times E$ interaction attributable to this source. Conversely, to the extent that the correlation among the performance of genotypes in different environments decreases, there will be a corresponding increase in $\mathrm{G} \times \mathrm{E}$ interaction. Therefore, $L\left(r_{\mathrm{g}}\right)$ is the component of $\mathrm{G} \times \mathrm{E}$ interaction that complicates selection, because it measures the degree to which performance in one environment fails to predict performance in the other. Conversely, the component attributable to heterogeneity of genetic variance will not directly affect selection decisions.

Another parameter describing the change of rankings among genotypes across environments is the Spearman rank correlation, which is estimated from clonal means in the two environments by PROC CORR (sAs Institute, 1988). Its significance test is based on deviation from unity. A simple nonparametric approach to this test is to construct a null data matrix based on rearranging the identities of each genotype so that the observed rank correlation between genotypic means equals 1 . The null data set for each genotype within each environment is then resampled with replacement, and a corresponding rank correlation calculated. This process is repeated to construct a 'bootstrapped' (Efron, 1982) null distribution of rank correlations, to which the observed rank correlation is compared. The proportion of simulated values falling below the observed values is then treated as a one-tailed probability level for the test.

The relationships of mean performance between the two locations (Boardman and Clatskanie) were fitted by regression equations in the $F_{2}$ families. The best regression model was found to be linear for stem height, exponential for basal area, and a thirdorder polynomial for stem proportion. The coefficients of determination, $r^{2}$, describing the degree to which observed values deviate from the fitted regression lines, were calculated for the three traits.

Broad-sense heritabilities on a clonal mean basis were estimated for each environment and across the two environments, respectively. In both cases, the among-replicate variance was included in the estimates of heritability, which is different from many traditional analyses in forest trees (Dean et al.,
1986). The omission of this variance from the total phenotypic variance might lead to inflated estimates of heritability when variation among replicates accounts for a large proportion of the total variance (Cotterill, 1987). The 'variance' attributable to the environment main effect was excluded from the estimates for the across-environment heritability because the effect was assumed to be fixed. The standard errors of broad-sense heritability on a clonal mean basis were calculated using a modified version of the method suggested in Singh et al. (1993).

In all the above statistical analyses, replicate IV in Boardman was ignored because it had a different watering regime from the other replicates in year 2 .

\section{Results and discussion}

\section{Environmental sensitivities and growth segregation}

Stem growth in both years was greater at Boardman than Clatskanie, but varied among the different materials (Fig. 2). The common $P$. trichocarpa female parent, 93-968, performed better than the two $P$. deltoides male parents, ILL-005 and ILL-129, in both locations in year 1 and at Clatskanie also in year 2 . The response of ILL-005 to the two environments paralleled that of ILL-129 in year 1 but differed in year 2. At Boardman, the $F_{1}$ hybrids from both families displayed strong hybrid vigour relative to the better parent, especially in basal area and volume index. However, that was not so at Clatskanie, where 2nd-year height growth increment of the female parent, 93-968, exceeded that of the best $F_{1}$ hybrid by $0.4 \mathrm{~m}$ (Fig. $2 \mathrm{~d}$ ). The two $F_{2}$ families had the lowest mean values in all growth traits, but the majority of $F_{2}$ genotypes showed strong responses to the environments (Fig. 2). In general, the Boardman environment was more favourable for all materials but proportionally more so for those containing some, or all, genes from $P$. deltoides. Least responsive, in relative terms, was the $P$. trichocarpa parent, originating from the cooler, mesic environment west of the Cascades.

The response of stem proportion to the two environments was a function of age. In year 1 , trees at Boardman were stouter than those at Clatskanie. That was still true in year 2 for the majority of $F_{2}$ trees but not for the parentals and $F_{1} S$ (data not shown). Stouter stems are commonly observed in windy locations such as Boardman (Niklas, 1992). This difference in stem form was well captured in year 1 when diameters were measured close to the base (see Materials and methods). Second-year 


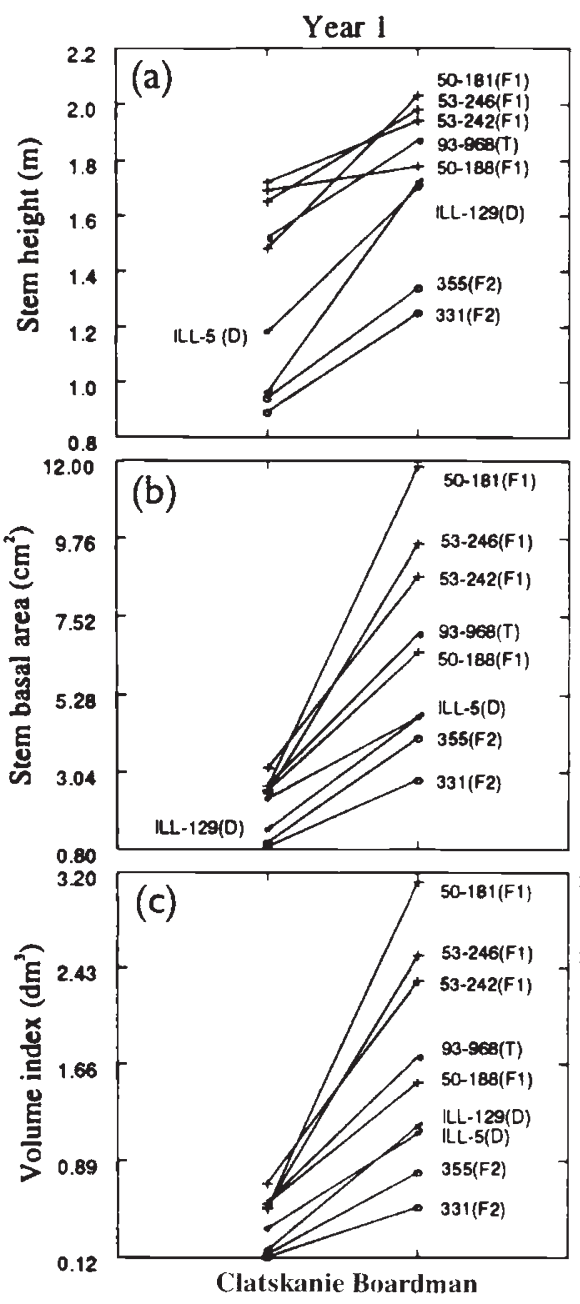

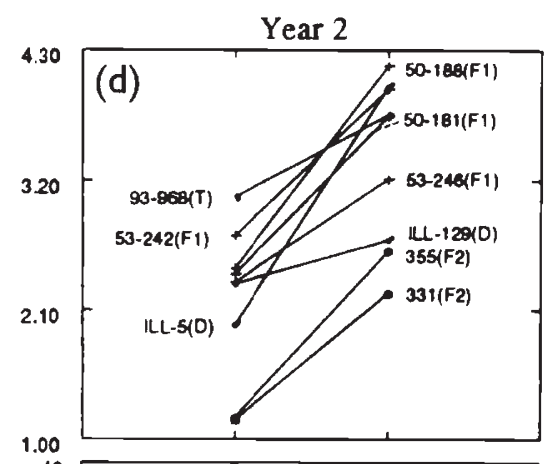

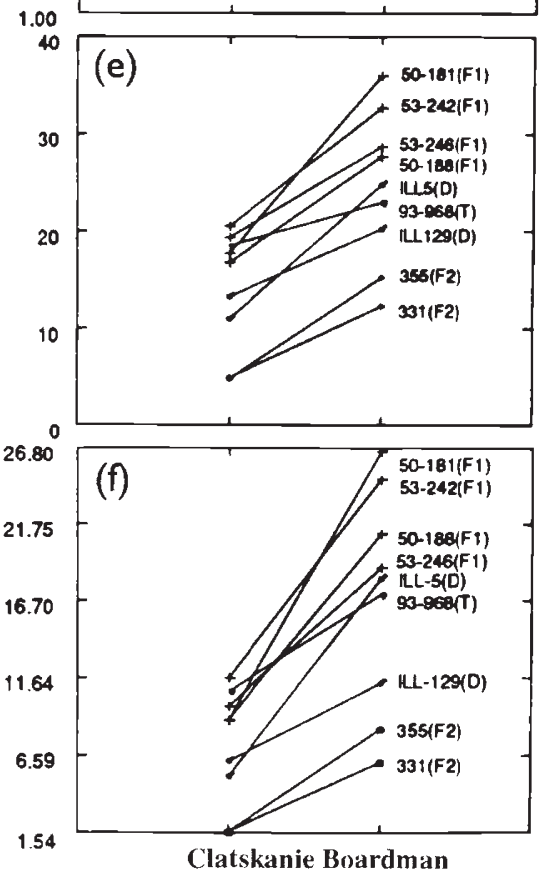

Fig. 2 Phenotypic means of stem traits at Boardman (east) and Clatskanic (west) in Populus trichocarpa (T, clone 93--968), P. deltoides (D, clones ILL-005 and ILL-129), the four $F_{1}$ hybrids (clones $50-181,50-188$. 53-242 and 53-246) and the two $F_{2}$ families (331 and 355). measurements (at mid-height of height increment in year 1) may have been less discriminating.

At Boardman, stem growth responded strongly to different replicates. In year 1 , when the four replicates received the same watering regime, there was a general trend of increasing growth from replicates I to IV. The same trend was evident in year 2, except that growth in replicate IV was markedly lower because of its reduced irrigation rate (data not shown). Sensitivity to light, temperature, water and nutrients has been demonstrated in many previous studies for Populus (Farmer, 1970; Hinckley et al., 1989; Drew \& Chapman, 1992; Dunlap et al., 1994). In a greenhouse study of $P$. deltoides, $P$. trichocarpa and their hybrids, Braatne et al. (1992) showed that leaf area and stem volume growth dramatically decreased with decreasing soil water potential.

Stem growth in both $F_{2}$ families displayed a continuous variation pattern, with much larger phenotypic ranges at Boardman than Clatskanie (shown in Fig. 3 for Family 331). Height variation showed a perfect normal distribution in both years and environments. Volume index, however, was skewed toward the low values in both years, especially at Clatskanie. The same trend, found earlier in the 1988 subset of Family 331 at Puyallup, was attributed to inbreeding depression in this family derived from a full-sib mating ( Wu \& Stettler, 1994; Bradshaw \& Stettler, 1995). But both Families 331 and 355 also had a few transgressants above the better parent for stem height and volume index in each year at Boardman. The two best genotypes of Family 331 at Boardman slightly exceeded the 2nd-year height and volume of even the $F_{1}$ (Fig. 3a,b).

\section{Nature of $G \times E$ interaction}

Genetic variation in reaction norm For all growth traits there were significant environment, genotype, replicate, genotype $\times$ environment, and genotype $\times$ replicate interaction effects in both $F_{2}$ families 
Fig. 3 Distribution of phenotypes for stem growth traits in Family 331 at Boardman (a and b) and Clatskanie (c and $d)$. The means of the original parents (Populus trichocarpa, T, and $P$. deltoides, $\mathrm{D}$ ), the $\mathrm{F}_{1}$ hybrids and the $\mathrm{F}_{2}$ family are indicated.
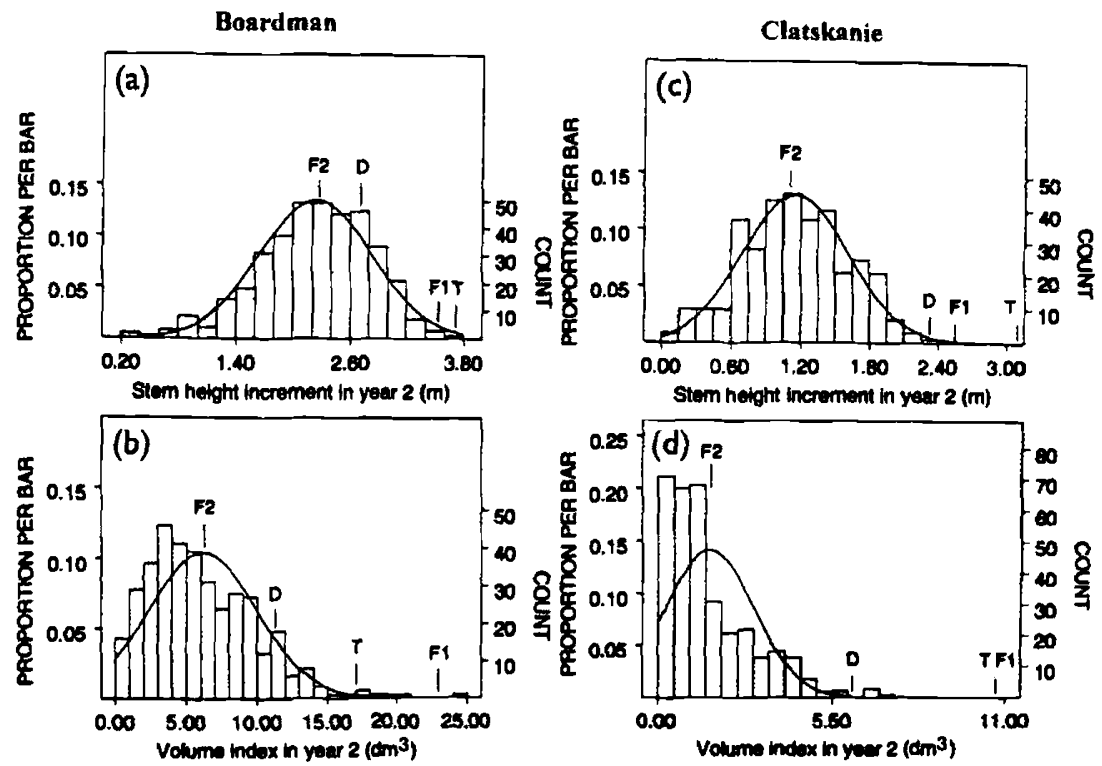

Table 1 Proportions of variance attributable to macroenvironment (E), replicate within macroenvironment (R/E), genotype $(\mathrm{G}), \mathrm{G} \times \mathrm{E}, \mathrm{G} \times \mathrm{R} / \mathrm{E}$, and error effects for stem traits of Populus during the first two years of growth in Families 331 and 355

\begin{tabular}{lcccccc}
\hline & $\mathrm{E}$ & $\mathrm{R} / \mathrm{E}$ & $\mathrm{G}$ & $\mathrm{G} \times \mathrm{E}$ & $\mathrm{G} \times \mathrm{R} / \mathrm{E}$ & Error \\
\hline Mean squares mode & $\mathrm{M}_{1}$ & $\mathrm{M}_{2}$ & $\mathrm{M}_{3}$ & $\mathrm{M}_{4}$ & $\mathrm{M}_{5}$ & $\mathrm{M}_{6}$ \\
F-statistics & $\left(\mathrm{M}_{3}+\mathrm{M}_{5}\right) /\left(\mathrm{M}_{2}+\mathrm{M}_{4}\right)$ & $\mathrm{M}_{2} / \mathrm{M}_{6}$ & $\mathrm{M}_{3} / \mathrm{M}_{6}$ & $\mathrm{M}_{4} / \mathrm{M}_{5}$ & $\mathrm{M}_{5} / \mathrm{M}_{6}$ & - \\
Family 331 & & & & & \\
HT year 1 & $0.31^{* * *}$ & $0.04^{* * *}$ & $0.31^{* * *}$ & $0.08^{* * *}$ & $0.06^{* * *}$ & 0.20 \\
HT year 2 & $0.53^{* * *}$ & $0.02^{* * *}$ & $0.26^{* * *}$ & $0.05^{* * *}$ & $0.07^{* * *}$ & 0.08 \\
HTI year 2 & $0.53^{* * *}$ & $0.03^{* * *}$ & $0.20^{* * *}$ & $0.06^{* * *}$ & $0.09^{* * *}$ & 0.10 \\
BA year 1 & $0.42^{* * *}$ & $0.07^{* * *}$ & $0.19^{* * *}$ & $0.08^{* * *}$ & $0.11^{* * *}$ & 0.14 \\
BA year 2 & $0.39^{* * *}$ & $0.02^{* * *}$ & $0.27^{* * *}$ & $0.10^{* * *}$ & $0.09^{* * *}$ & 0.13 \\
VOL year 1 & $0.33^{* * *}$ & $0.08^{* * *}$ & $0.20^{* * *}$ & $0.10^{* * *}$ & $0.14^{* * *}$ & 0.16 \\
VOL year 2 & $0.37^{* * *}$ & $0.02^{* * *}$ & $0.26^{* * *}$ & $0.13^{* * *}$ & $0.10^{* * *}$ & 0.12 \\
HDR year 1 & $0.26^{* * *}$ & $0.02^{* * *}$ & $0.17^{* * *}$ & $0.18^{* * *}$ & $0.06^{* * *}$ & 0.32 \\
HDR year 2 & $0.00 \mathrm{NS}$ & $0.00 \mathrm{NS}$ & $0.34^{* * *}$ & $0.14^{* * *}$ & $0.10^{* * *}$ & 0.42 \\
Family 355 & & & & & & \\
HT year 1 & & & & & \\
HT year 2 & $0.29^{* * *}$ & $0.04^{* * *}$ & $0.33^{* * *}$ & $0.09^{* * *}$ & $0.06^{* * *}$ & 0.19 \\
HTI year 2 & $0.65^{* * *}$ & $0.02^{* * *}$ & $0.19^{* * *}$ & $0.05^{* * *}$ & $0.04^{* * *}$ & 0.06 \\
BA year 1 & $0.67^{* * *}$ & $0.03^{* * *}$ & $0.14^{* * *}$ & $0.04^{* * *}$ & $0.05^{* * *}$ & 0.08 \\
BA year 2 & $0.47^{* * *}$ & $0.07^{* * *}$ & $0.16^{* * *}$ & $0.09^{* * *}$ & $0.08^{* * *}$ & 0.14 \\
VOL year 1 & $0.57^{* * *}$ & $0.03^{* * *}$ & $0.18^{* * *}$ & $0.07^{* * *}$ & $0.05^{* * *}$ & 0.12 \\
VOL year 2 & $0.35^{* * *}$ & $0.08^{* * *}$ & $0.18^{* * *}$ & $0.12^{* * *}$ & $0.11^{* * *}$ & 0.15 \\
HDR year 1 & $0.51^{* * *}$ & $0.03^{* * *}$ & $0.18^{* * *}$ & $0.11^{* * *}$ & $0.06^{* * *}$ & 0.12 \\
HDR year 2 & $0.46^{* * *}$ & $0.01 \mathrm{NS}$ & $0.10^{* * *}$ & $0.10^{* * *}$ & $0.03^{* * *}$ & 0.30 \\
\hline
\end{tabular}

HT, stem height; HTI, stem height increment; BA, stem basal area measured at $3 \mathrm{~cm}$ above the ground in year 1 and at the mid-point of HTI in year 1; VOL, stem volume index; HDR, stem height:diameter ratio.

*** Significant at $P<0.001$; NS nonsignificant.

(Table 1). Furthermore, the variance components of the various main and interaction effects were proportionately similar between the two families. In most cases, environmental difference accounted for the highest proportion of the total observed variance ( $\approx 30-65$ per cent), followed by genotypic difference ( $\approx 15-30$ per cent). Genotype $\times$ environment and genotype $\times$ replicate interactions explained smaller

(C) The Genetical Society of Great Britain, Heredity, 78, 124-134. 
proportions, both ranging from 5 to 18 per cent. The variance attributable to the small-scale withinenvironment effects of replicates was the smallest (2-8 per cent).

The fractions of the total variance in stem proportion explained by environment and genotype effects varied over the two years. The genotype effect on this trait in year 2 at least doubled that in year 1 . Conversely, environmental influences were negligible in year 2, despite substantial magnitude in year 1.

Genetic correlations in stem traits between the two environments also showed parallel patterns in the two $\mathrm{F}_{2}$ families (Table 2). All correlations differed significantly from zero, suggesting that at least part of the genetic response to the two locations was shared. Stem basal area and volume in year 1 tended to have the same genetic foundation in the two environments because the genetic correlations were not significantly less than unity. For the other traits with the correlations significantly less than 1, different genetic expression was expected in the two environments. For stem proportion in year

Table 2 Genetic correlations $\left(r_{\mathrm{g}}\right)$, the relative percentages of $\mathrm{G} \times \mathrm{E}$ interaction attributable to the lack of genetic correlation $\left[L\left(r_{\mathrm{g}}\right)\right]$ and Spearman rank correlations $\left(r_{\mathrm{S}}\right)$ of clonal means between the Boardman and Clatskanic Populus plantations for stem traits in the two $F_{2}$ families

\begin{tabular}{lcrc}
\hline Trait & $r_{\mathrm{g}}$ & $L\left(r_{\mathrm{g}}\right)$ & $r_{\mathrm{S}}$ \\
\hline Family 331 & & & \\
HT year 1 & $0.575^{* * * \dagger}$ & 96.1 & $0.664 \dagger$ \\
HT year 2 & $0.652^{* * * \dagger}$ & 89.6 & $0.677 \dagger$ \\
HTI year 2 & $0.507^{* * * \dagger}$ & 87.0 & $0.553 \dagger$ \\
BA year 1 & $0.885^{* * *}$ & 7.4 & $0.705 \dagger$ \\
BA ycar 2 & $0.558^{* * * \dagger}$ & 53.8 & $0.647 \dagger$ \\
VOL year 1 & $0.930^{* * *}$ & 6.4 & $0.697 \dagger$ \\
VOL year 2 & $0.636^{* * * \dagger}$ & 26.1 & $0.662 \dagger$ \\
HDR year 1 & $-0.321^{* * *}+$ & 78.9 & $0.342 \ddagger$ \\
HDR year 2 & $0.340^{* * * \dagger}$ & 96.8 & $0.475 \ddagger$ \\
Family 355 & & & \\
HT year 1 & $0.523^{* * * \dagger}$ & 98.4 & $0.649 \dagger$ \\
HT year 2 & $0.591^{* * * \dagger}$ & 86.3 & $0.651 \dagger$ \\
HTI year 2 & $0.508^{* * * \dagger}$ & 81.2 & $0.557 \dagger$ \\
BA year 1 & $0.850^{* * *}$ & 8.2 & $0.648 \dagger$ \\
BA year 2 & $0.757^{* * * \dagger}$ & 22.6 & $0.596 \dagger$ \\
VOL year 1 & $0.987^{* * *}$ & 0.5 & $0.677 \dagger$ \\
VOL year 2 & $0.864^{* * *}$ & 6.5 & $0.626 \dagger$ \\
HDR year 1 & $-0.255^{* * *}+$ & 78.1 & $0.309 \dagger$ \\
HDR year 2 & $0.236^{* * *}+$ & 87.8 & $0.455 \dagger$ \\
\hline
\end{tabular}

See explanation for traits in Table 1 .

***Correlation is greater than zero at $P<0.001$.

†Correlation is less than unity at $P<0.05$.

+ Correlation is less than unity at $P<0.01$.
1, there was a genetically based trade-off: slender stems attained at Boardman were genetically associated with stouter stems attained at Clatskanie, and vice versa.

In both $F_{2}$ families, a much higher percentage of $\mathrm{G} \times \mathrm{E}$ interaction variance for stem height was associated with the lack of genetic correlation across the environments $\left[L\left(r_{\mathrm{g}}\right)=81-98\right.$ per cent $]$ than with the heterogeneity of genetic variance between the environments (Table 2). In other words, height growth at Clatskanie would be a poor predictor of height growth at Boardman. By contrast, the $L\left(r_{\mathrm{g}}\right)$ values for basal area were much lower (7-54 per cent), indicating more consistent performance of genotypes across environments in that trait. Judging from the moderate genetic correlations across environments (Table 2), not all genetic loci for height and basal area were shared in the two environments. In height, nonshared genetic loci may be a major cause leading to $\mathrm{G} \times \mathrm{E}$ interactions, whereas significant $G \times E$ interactions in basal area may result from differential expression of the shared genetic loci in the two environments. This hypothetical genetic mechanism can be tested by molecularmarker-based mapping of the same material (see also Paterson et al., 1991; Stuber et al., 1992). $\mathrm{G} \times \mathrm{E}$ interactions for volume were similar to those for basal area, showing greater consistency between environments than stem proportion (Table 2).

'Cross-over' or qualitative interactions The Spearman rank correlations between clonal means in the two environments were positive, moderately high and significant, but also significantly less than unity (Table 2). Hence, there were changes in the ranks of clones between the two locations but no general genotypic trade-off in performance. This is illustrated by Fig. 4 in which all clones of Family 331 are plotted for Boardman and Clatskanie; many clones deviate considerably from a putative regression line. For example, genotypes $\mathrm{x}$ and $\mathrm{y}$, both having closeto-average basal areas at Clatskanie, showed highly contrasting radial growth at Boardman (Fig. 4e). Rank changes were found to differ between slowand fast-growing genotypes. From the 25 smallestvolume $F_{2}$ genotypes of Family 331 at Boardman, 16 were found to be dead in year 2 at Clatskanie and two to have the lowest volume. By contrast, from the 25 best $F_{2}$ genotypes for volume at Boardman, only nine were also in the top 25 at Clatskanie. Thus, slow-growing genotypes performed poorly in both places, whereas fast-growing genotypes varied in their relative superiority in the two environments. Similar trends held also for Family 355 (see Wu, 1995). It is tempting to consider poor performers in 
Year 1
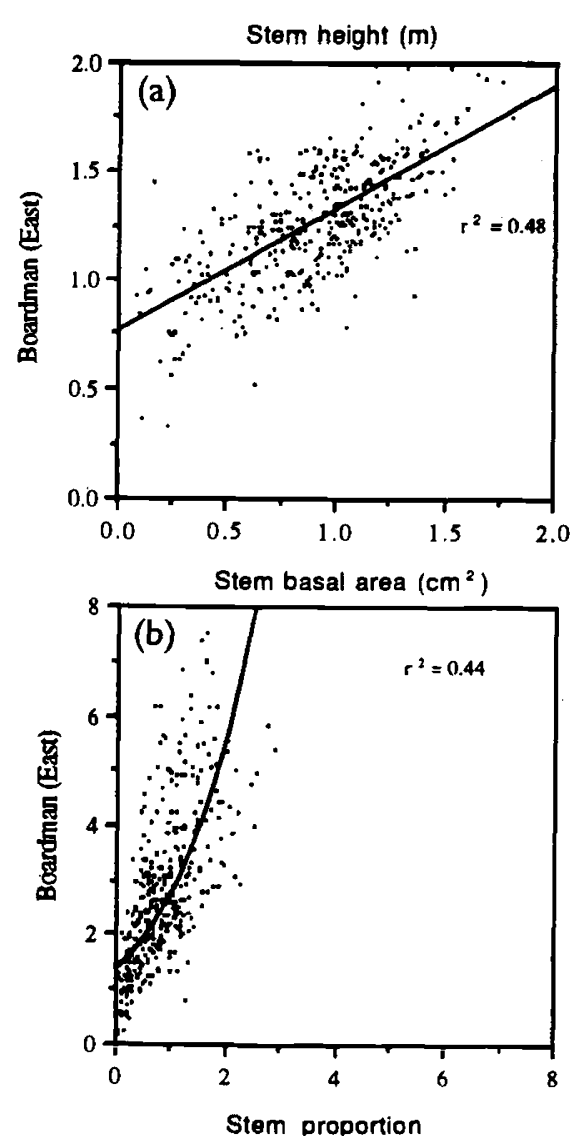

Fig. 4 Phenotypic means of stem height ( $a$ and $d)$, basal area (b and e) and proportion ( $\mathrm{c}$ and $\mathrm{f}$ ) for all members of Populus $\mathrm{F}_{2}$ Family 331, planted at Boardman (east) and Clatskanie (west). The regression analysis of Boardman on Clatskanie is performed by a linear model for stem height and proportion and by an exponential model for basal area. The coefficients of determination, $r^{2}$, for all regression analyses are given.
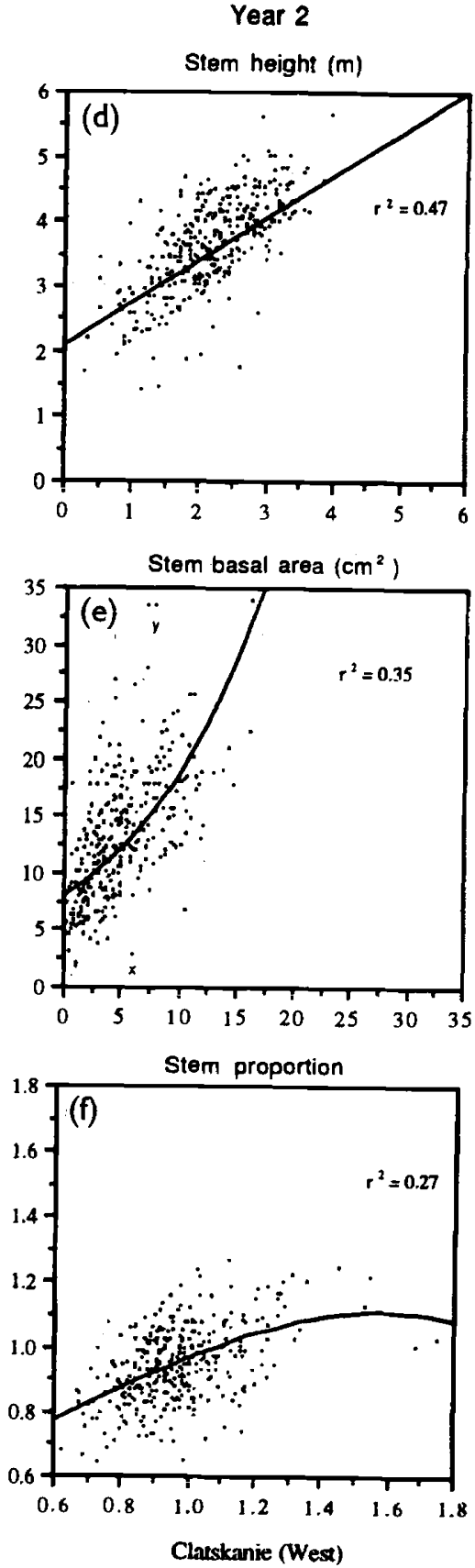

both environments as affected by deleterious recessives as a result of inbreeding. However, they also may represent unfavourable recombinants in which developmental disharmony was able to express itself. Only a comparative study with an outbred pedigree will help to elucidate this question.

\section{Environmental heterogeneity and its impact on broad-sense heritability}

At both Boardman and Clatskanie, a two-way analy- sis of variance was used to detect the effects attributable to genotype, replicate, and genotype $x$ replicate interactions on stem growth. All effects were remarkably concordant between the two $F_{2}$ families (see Wu, 1995). In all cases, replicate effects for replicates I-III were significant at Boardman and explained larger percentages of the total phenotypic variance $(1-14$ per cent) than at Clatskanie $(0-2$ per cent $)$. For most traits, genotype $\times$ replicate interactions accounted for a significant amount of the phenotypic variance, with generally larger values 
at Boardman (10-22 per cent) than at Clatskanie (5-17 per cent). The components of variance from these two sources differed between the two years, depending on growth environments. Replicate effects had decreased at Boardman but increased at Clatskanie by year 2 . Genotype $\times$ replicate interactions were larger in year 2 than year 1 at Clatskanie, whereas at Boardman the pattern of change over years depended on the traits.

All traits displayed high broad-sense heritabilities on a clonal mean basis $\left(H^{2}\right)$ in each environment, ranging from $0.70-0.90$ (data not shown, but see $\mathrm{Wu}, 1995)$. Significant differences in $H^{2}$ values were found between environments and years, as tested by the bootstrap method (Mitchell-Olds, 1986). Heritabilities at Boardman were less than those at Clatskanie in year 1 but exceeded them in year 2. This came about by a systematic increase in values at Boardman, combined with a partial decrease at Clatskanie, especially in Family 355.

Broad-sense heritabilities for these two plantations were larger than those calculated for a subset of Family 331 planted 2 years earlier at Puyallup, Washington (Wu \& Stettler, 1994). Differences in heritability between environments may be a consequence of differences in either genetic variance or environmental variance, or both, across these environments (Falconer, 1989). Environmental heterogeneity is considered by some authors to increase phenotypic variance through an increase in the environmental components of variance, especially in traits that are phenotypically plastic (Mitchell-Olds \& Rutledge, 1986; Bazzaz et al., 1990). This prediction is partly supported by our data in which lower heritabilities in first-year stem traits at Boardman than Clatskanie were also associated with greater microenvironmental heterogeneity (see $\mathrm{Wu}, 1995$ ). But we also found that environment was inducing changes in the genetic component of variation in the $\mathrm{F}_{2}$ families (Table 3 ). Genetic variances for growth traits, especially basal area and volume index, were substantially larger in the warm, high-radiation, and well-watered regime of the interior (Boardman) than in the cooler coastal conditions of Clatskanie. The direction of acrossenvironment change in genetic variance for a quantitative trait depends on how the number of genes underlying the trait and/or their expression change

Table 3 Genetic variances $( \pm \mathrm{SE}$ ) and across-environment broad-sense heritabilities for stem traits of Populus in Families 331 and 355 at Boardman and Clatskanie

\begin{tabular}{lrcc}
\hline & \multicolumn{2}{c}{ Genetic variance } & \\
Trait & \multicolumn{1}{c}{ Boardman } & Clatskanie & $\begin{array}{c}\text { Heritability } \\
\text { pooled }\end{array}$ \\
\hline Family 331 & & & \\
HT year 1 & $0.0673 \pm 0.0021$ & $0.0874 \pm 0.0032$ & $0.511 \pm 0.094$ \\
HT year 2 & $0.5293 \pm 0.0310$ & $0.3544 \pm 0.0214$ & $0.578 \pm 0.103$ \\
HTI year 2 & $0.2598 \pm 0.0091$ & $0.1511 \pm 0.0098$ & $0.461 \pm 0.120$ \\
BA year 1 & $2.2860 \pm 0.0641$ & $0.2360 \pm 0.0105$ & $0.404 \pm 0.110$ \\
BA year 2 & $28.7975 \pm 0.2100$ & $8.5563 \pm 0.0978$ & $0.456 \pm 0.100$ \\
VOL year 1 & $0.1073 \pm 0.0021$ & $0.0153 \pm 0.0010$ & $0.372 \pm 0.099$ \\
VOL year 2 & $12.6073 \pm 0.1023$ & $1.7936 \pm 0.0106$ & $0.413 \pm 0.104$ \\
HDR year 1 & $0.0084 \pm 0.0006$ & $0.0271 \pm 0.0016$ & $0.265 \pm 0.013$ \\
HDR year 2 & $0.0110 \pm 0.0009$ & $0.0148 \pm 0.0009$ & $0.450 \pm 0.053$ \\
Family 355 & & & \\
HT year 1 & $0.0998 \pm 0.0020$ & $0.0835 \pm 0.0019$ & $0.512 \pm 0.101$ \\
HT year 2 & $0.5427 \pm 0.0103$ & $0.3268 \pm 0.0127$ & $0.518 \pm 0.132$ \\
HTI year 2 & $0.2678 \pm 0.0081$ & $0.1368 \pm 0.0100$ & $0.469 \pm 0.178$ \\
BA year 1 & $3.1236 \pm 0.0214$ & $0.2734 \pm 0.0120$ & $0.367 \pm 0.153$ \\
BA year 2 & $29.6535 \pm 0.3100$ & $5.0801 \pm 0.0410$ & $0.344 \pm 0.136$ \\
VOL year 1 & $0.2177 \pm 0.0023$ & $0.0113 \pm 0.0012$ & $0.337 \pm 0.149$ \\
VOL year 2 & $15.8200 \pm 0.1203$ & $1.1657 \pm 0.0100$ & $0.378 \pm 0.147$ \\
HDR year 1 & $0.0053 \pm 0.0006$ & $0.0171 \pm 0.0012$ & $0.252 \pm 0.198$ \\
HDR year 2 & $0.0071 \pm 0.0007$ & $0.0136 \pm 0.0011$ & $0.382 \pm 0.120$ \\
\hline SE expatan & & &
\end{tabular}

See explanation for traits in Table 1. 
over environments (Falconer, 1989). A molecular study, currently underway, will shed light on this question (H. D. Bradshaw, Jr, unpublished results).

As expected, all heritabilities for the pooled data across the two plantations were lower (ranging from $0.25-0.58)$ than those calculated for each plantation (Table 3 ). The pooled values are suggested to be more accurate estimates because they are not affected by possible genotype $\times$ macroenvironment interactions. Even the pooled estimates of broad-sense heritabilities in the present study are larger than those reported in many previous studies on Populus (Farmer \& Wilcox, 1968; Ying \& Bagley, 1976; Foster, 1986; Nelson \& Tauer, 1987; Rogers et al., 1989). This is not surprising because our material represents interspecific $F_{2}$ progenies, whereas other studies included open-pollinated progenies of single species or progenies of interpopulation crosses. $F_{2}$ generations are inherently varied, because of segregation and recombination, especially if derived from highly distinct species as in the present case (Eckenwalder, 1977). It should be noted that our broadsense heritability estimates are specific to the two pedigrees and contingent upon the assumption that all QTLs are fixed for alternative alleles in the parents used for the original crosses.

\section{Implications for breeding and selection}

This study of two interspecific $F_{2}$ pedigrees in two contrasting environments has revealed significant $\mathrm{G} \times \mathrm{E}$ interactions of $\approx 10$ per cent of the total phenotypic variance during the first two years of growth. At the same time it has confirmed what general productivity studies with $F_{1}$ hybrids of the same or similar original parentage have shown earlier, namely that individual genotypes can be selected that perform well in both locations (Stettler et al., 1988). In fact, a few such $F_{1}$ hybrids have been adopted as choice clones by commercial growers in the Pacific Northwest and have demonstrated adaptability to a broad range of conditions east and west of the Cascade Range.

The use of interspecifc $F_{2}$ families has offered additional insights gained from genetic segregation and recombination. Partitioning of $\mathrm{G} \times \mathrm{E}$ interactions in that material has indicated that of the two growth components, radial growth had a more consistent response across the two environments than height growth. Thus, selection for good performers in radial growth conducted in one location would arrive at essentially the same selections if conducted at the other; whereas this would be less true for height. The more favourable conditions at
Boardman greatly amplified the genetic variance and, thus, would be the more suitable of the two environments in which to conduct selection for radial growth and volume. One limitation of that environment, however, would be its lower pathogen pressure, an important selective force affecting productivity in the moister climate west of the Cascades (Newcombe \& Chastagner, 1993). Although 2-year data point to the existence of a few 'generalist' clones that perform well in both environments, eventual gains may be greater with a breeding strategy that favours 'specialist' clones for each.

Breeding has been initiated to validate the present study with outcrossed $F_{2}$ pedigrees.

\section{Acknowledgements}

We wish to thank S. Wolpow and J. Whisler for technical assistance; Boise Cascade Corporation and James River Corporation for plantation maintenance; and Drs H. D. Bradshaw, Jr and B. J. Stanton, and two anonymous reviewers for helpful comments on the manuscript. This work has been supported through grants from the US Department of Energy (19X-43382C) and the Washington Technology Center (09-1022).

\section{References}

ABELSON, P. 1991. Improved yields of biomass. Science, 252, 1469.

ALLARD, R. E. AND BRADSHAW, R. w. 1964. Implications of genotype-environment interactions in applied plant breeding. Crop Sci., 4, 503-508.

BAZZAZ, F. A., COLEMAN, J. S. AND MORSE, S. R. 1990. Growth responses of seven major co-occurring tree species of the northeastern USA to elevated carbon dioxide. Can. J. Forest Res., 20, 1479-1484.

BRAATNE, J. H., HINCKLEY, T. M. AND STETTLER, R. F. 1992. The influence of soil moisture on the physiological and morphological components of plant water balance in Populus trichocarpa, $P$. deltoides, and their $F_{1}$ hybrids. Tree Physiol., 11, 325-339.

BRADSHAW, H. D., JR AND STETTLER, R. F. 1993. Molecular genetics of growth and development in Populus. I. Triploidy in hybrid poplars. Theor. Appl. Genet., 86, 301-307.

BRADSHAW, H. D., JR AND STETTLER, R. F. 1995. Molecular genetics of growth and development in Populus. IV. Mapping QTLs with large effects on growth, form, and phenology traits in a forest tree. Genetics, 139, 963-973. COOPER, M. AND DELACY, I. H. 1994. Relationships among analytical methods used to study genotypic variation and genotype-environment interaction in plant breeding multi-environment experiments. Theor. Appl. Genet., 88, 561-572. 
COTTERILL, P. P. 1987. On estimating heritability according to practical applications. Silvae Genet., 36, 46-48.

DEAN, C. A., COTTERILl, P. P. AND EISEMANN, R. L. 1986. Genetic parameters and gains expected from selection in Pinus caribaea var. hondurensis in northern Queensland, Australia. Silvae Genet., 35, 229-236.

DREW, A. P. AND CHAPMAN, J. A. 1992. Inheritance of temperature adaptation in intra- and inter-specific Populus crosses. Can. J. Forest Res., 22, 62-67.

DUNLAP, J. M., HEILMAN, P. E. AND STETTLER, R. F. 1994. Genetic variation and productivity of Populus trichocarpa and its hybrids. VII. Survival and 2-year growth of native black cottonwood clones from four river valleys in Washington. Can. J. Forest Res., 24, 1539-1549.

ECKENWALdER, J. E. 1977. Systematics of Populus L. (Salicaceae) in Southwestern North America, with Special Reference to Section Aigeiros Duby. Ph. D. Dissertation, University of California, Berkeley.

EFrON, B. 1982. The Jackknife, the Bootstrap and Other Resampling Plans. SIAM (Society for Industrial and Applied Mathematics), Philadelphia, PA.

FALCONER, D. S. 1989. Introduction to Quantitative Genetics, 4th edn. Longman Scientific and Technical, London.

FARMER, R. E., JR. 1970. Variation and inheritance of eastern cottonwood growth and wood properties under two soil moisture regimes. Silvae Genet., 19, 5-9.

FARMER, R. E., JR AND Wilcox, J. R. 1968. Preliminary testing of eastern cottonwood clones. Theor. Appl. Genet., 38, 197-201.

FOSTER, G. S. 1986. Provenance variation of eastern cottonwood in the lower Mississippi Valley. Silvae Genet., 35, 32-38.

HEILMAN, P. E. AND STETTLER, R. F. 1990. Genetic variation and productivity of Populus trichocarpa and its hybrids. IV. Performance in short rotation coppice. Can. J. Forest Res., 20, 1257-1264.

HINCKLEY, T. M., CEULEMANS, R., DUNLAP, J. M., FIGLIOLA, A., Hellman, P. E., ISEBRANDS, J. G. ET AL. 1989. Physiological, morphological and anatomical components of hybrid vigor in Populus. In: Kreeb, K. H., Richter, H. and Hinckley, T. M. (eds) Structural and Functional Responses to Environmental Stresses, pp. 199-217. SPB Academic Publishing, The Hague.

LEDIG, F. T. 1970. Genotype $\times$ environment interaction in controlled environments: the physiological basis for differential response. In: Second Meeting of the Working Group on Quantitative Genetics, Section 22, IUFRO 1969, pp. 90-99. USDA Forest Service, Southern For. Exp. Sta., New Orleans, LA.

MATHER, K. AND JinKS, J. L. 1982. Biometrical Genetics, 3rd edn. Chapman and Hall, London.

MITCHELL-OLDS, T. 1986. Quantitative genetics of survival and growth in Impatiens capensis. Evolution, 40, $107-116$.

MitCHELl-OLDS, T. AND RutLedGe, J. 1986. Quantitative genetics in natural plant populations: a review of theory. Am. Nat., 127, 379-402.
NAMKOONG, G. AND CONKLE, M. T. 1976. Time trends in genetic control of height growth in ponderosa pine. Forest Sci., 22, 2-12.

NAMKOONG, G., JONSSON, A. AND ERIKSSON, G. 1992. Genetic variation in nutrient response functions. Theor. Appl. Genet., 85, 165-172.

NELSON, C. D. AND TAUER, C. G. 1987. Genetic variation in juvenile characters of Populus deltoides Bartr. from the southern Great Plains. Silvae Genet., 36, 216-221.

NewCOMBE, G. AND CHAstagner, G. A. 1993. A leaf-rust epidemic of hybrid poplar along the lower Columbia River caused by Melampsora medusae. Plant Disease, 77, 528-531.

N1KLAS, K. J. 1992. Plant Biomechanics. The University of Chicago Press, Chicago and London.

PATERSON, A. H., DAMON, S. HEWITT, J. D., ZAMIR, D., RABINOWITCH, H. D., LINCOLN, S. E. ET $A L$. 1991. Mendelian factors underlying quantitative traits in tomato: comparison across species, generations, and environments. Genetics, 127, 181-197.

RANNEY, J. W., WRIGHT, L. L. AND LAYTON, P. A. 1987. Hardwood energy crops: the technology of intensive culture. J. For, 85, 17-28.

ROBERTSON, A. 1959. The sampling variance of the genetic correlation coefficient. Biometrics, 15, 469-485.

ROGERS, D. L., STETTLER, R. F. AND HEILMAN, P. E. 1989. Genetic variation and productivity of Populus trichocarpa (T. \& G.) and its hybrids. III. Structure and pattern in a three year field test. Can. J. Forest Res., 19, 372-377.

SAS INSTItUTE. 1988. SAS Users' Guide: Statistics. SAS Institute, Cary, NC.

SiNGH, M., CECCARELli, S. AND HAMBLIN, J. 1993. Estimation of heritability from varietal trial data. Theor. Appl. Genet., 86, 437-441.

STETTLER, R. F., HEILMAN, P. E., FENN, R. AND STANTON, B. 1988. Populus trichocarpa $\times$ Populus deltoides hybrids for short rotation culture: variation patterns and four-year field performance. Can. J. Forest Res., 18, 745-753.

STUBER, C. W., LINCOLN, S. E., WOLFF, D. W., HELENTJARIS, T. AND LANDER, E. S. 1992. Identification of genetic factors contributing to heterosis in a hybrid from two elite maize inbred lines using molecular markers. Genetics, 132, 823-839.

VIA, S. AND LANDE, R. 1985. Genotype-environment interaction and the evolution of phenotypic plasticity. Evolution, 39, 505-522.

wU, R. 1995. The Genetic Dissection of Growth and Development in Populus. Ph.D. Dissertation, University of Washington, Seattle.

WU, R. AND STETTLER, R. F. 1994. Quantitative genetics of growth and development in Populus. I. A three-generation comparison of tree architecture during the first two years of growth. Theor. Appl. Genet., 88, 1046-1054.

YING, C. C. AND BAGLEY, w. 1976. Genetic variation of eastern cottonwood in an eastern Nebraska provenance study. Silvae Genet., 25, 67-73. 